\title{
COARCTATION OF THE AORTA IN OLDER PATIENTS
}

\author{
BY \\ F. T. I. OEY AND J. A. NOORDIJK \\ From the Department of Thoracic Surgery of the University Hospital, Leiden, Netherlands
}

(RECEIVED FOR PUBLICATION DECEMBER 12, 1960)

Coarctation of the aorta has received increasing clinical attention since its surgical treatment has become possible (Crafoord and Nylin, 1945; Gross and Hufnagel, 1945). The diagnosis generally offers no difficulty, but the question as to whether and when a patient with this condition should be submitted to operation is not always readily answered. In this connexion it is important to know the expectation of life in a case of coarctation of the aorta not submitted to an operation; the mortality of surgical treatment in these cases; and the results obtained by resection of the stenosis.

As early as 1928, investigations made by Hamilton and Abbott showed that the average age of untreated patients was 33.5 years, and Reifenstein, Levine, and Gross (1947) found an average of 35 years in 104 post-mortem cases. Since the mortality of the operation in uncomplicated cases in the favourable age group has become low, the general opinion is that patients in whom coarctation has been diagnosed should be considered for surgical treatment. Some maintain, however, that no operation must be resorted to in patients over 25 years of age who are asymptomatic. In 1948, Newman reported on the results of his investigations in 23 older patients with coarctation of the aorta. Three had been soldiers during the first world war. Of these three, one died at the age of 68. This led the author to the conclusion that the prognosis of coarctation of the aorta in older subjects is not so unfavourable if the condition does not give rise to symptoms before the age of 25 , but it should be pointed out that Newman's series is too small to sustain his conclusion. Bramwell (1947) also believed that the expectation of life in patients with coarctation of the aorta was good if the condition caused no symptoms before the thirtieth year of life. Gross (1953) maintained that the operation should preferably not be performed in patients over 25 years of age because, in these patients, the aorta often already shows such changes as increase the risk entailed by a vascular suture. Groves and Effler (1960) reported on three surgical patients more than 45 years of age. Two of these died, one as a result of mycotic aneurysm and the other because of encephalomalacia of the right cerebral hemisphere. The authors believed that the cause should be found in the inadequate oxygen supply to the markedly arteriosclerotic cerebrum as a result of the decrease in blood pressure in the upper half of the body after the operation. They believed that no rules should be set up regarding an age limit ; each case should be individually evaluated. We, too, were reserved in determining surgical indications in older patients with asymptomatic coarctation of the aorta. The case histories of the following patients show, however, that coarctation of the aorta can cause vitally dangerous complications even if it causes no symptoms or does so only at a more advanced age.

\section{CASE Reports}

The first patient was a man aged 52, with a 10 -year history of progressive dyspnoea and a tight feeling in the throat. He had a stridor. The brachial blood pressure was $200 / 100 \mathrm{~mm}$. Hg. No pulsations were palpable in the femoral artery.

A thoracic radiograph revealed a well-defined tumour in the mediastinum, with a diameter of about $10 \mathrm{~cm}$. (Fig. 1). The trachea showed antero-lateral displacement and marked flattening (Fig. 2), and the oesophagus anterior displacement and stenosis. Unmistakable coarctation of the aorta was found at operation. About $1 \mathrm{~cm}$. distal to the stenosis there was an aneurysm with a diameter of $10 \mathrm{~cm}$., which was proved to arise from the first right intercostal artery beyond the stenosis. Resection of the stenosis was difficult, as was ligation of this intercostal artery distal to the aneurysm. Part of the wall of the aneurysm was removed, and the continuity of the aorta was restored by an end-to-end anastomosis.

Progressive renal insufficiency occurred on the second post-operative day and was manifested by a progressive decrease in diuresis and an increase in blood urea concentration. The patient died on the sixth post-operative day. Post-mortem examination revealed that the anastomosis was occluded by a thrombus. (This is the only case in which we have seen this complication.) 


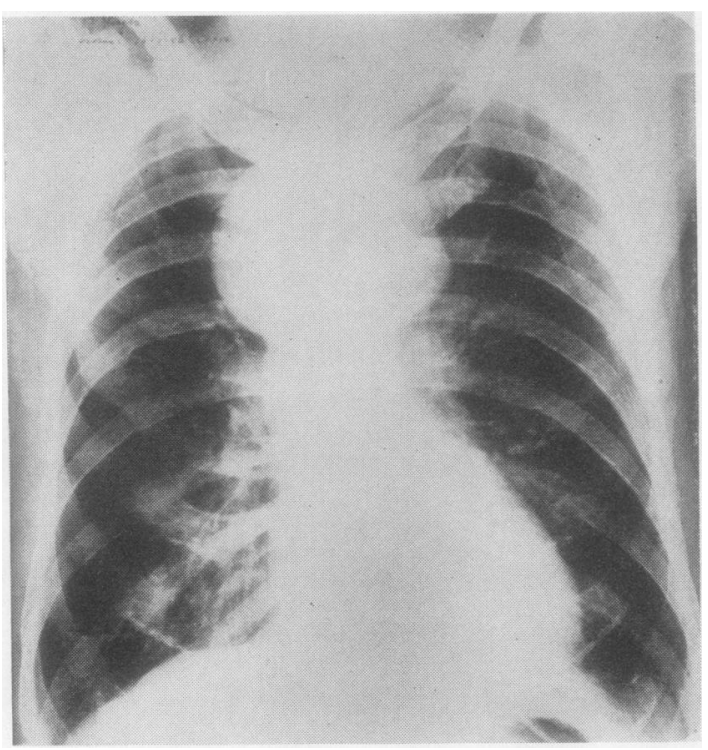

FIG. 1.-Well-defined intramediastinal tumour caused by an aneurysm arising from the first right intercostal artery beyond the stenosis.

The second patient was an agricultural worker who, on the occasion of a medical examination in 1952, was found to be hypertensive. At the time he was 27 years old and doing heavy work as an agriculturist. The only symptom reported was a vague headache. The blood pressure was $185 / 100 \mathrm{~mm}$. $\mathrm{Hg}$ in the arms and $90 / 70 \mathrm{~mm} . \mathrm{Hg}$ in the legs. The angiocardiogram demonstrated a coarctation of the aorta. At the time he was advised against an operation because he had no symptoms and could cope with his work.

In September, 1956, he was admitted elsewhere with sepsis. Haemolytic streptococci were twice cultured from the blood. Radiographs at that time revealed a small aneurysm. In view of the clinical picture, it was assumed that the aneurysm had become infected. It was decided that the sepsis should be controlled first, but the fever persisted despite large doses of antibiotics. Two months later the patient suddenly developed pain in the left axillary region and had a haemoptysis. A radiograph showed that the aneurysm had increased in volume (Fig. 3). An emergency operation was performed and a pulsating aneurysm with a diameter of about $10 \mathrm{~cm}$. was palpated in the upper lobe of the left lung, and the lower lobe was adherent to the descending aorta. As the aorta was being dissected free, cyanosis occurred and the blood pressure fell. Ventilation proved difficult, and we failed to improve it. Its cause was the pressure exerted by the aneurysm on the carina. Dissection of the aorta was continued, after which the stenosis was removed with the aneurysm, which was found to arise from a lateral branch of the aorta distal to the stenosis. The continuity of the aorta was restored by an end-to-end anastomosis. The period of anoxia had been too long, however, and the patient died after a few hours without having regained consciousness.

The third patient was a 42-year-old woman, whose $\overline{\bar{\sigma}}$ symptoms of fatigue, headache, and sometimes $\frac{\bar{c}}{2}$ tinnitus had started only a few months before $\stackrel{\Phi}{\Phi}$ admission. The blood pressure was $215 / 95 \mathrm{~mm}$. $\mathrm{Hg}_{\stackrel{\mathrm{O}}{ }}$ in the arms and $130 / 90 \mathrm{~mm}$. $\mathrm{Hg}$ in the legs.

At operation an aneurysm the size of a plum was $\overrightarrow{0}$ found in the aorta immediately past Botal's ligament, $\rightarrow$ at the side of the jet lesion. A second, equally large $\vec{\omega}$ aneurysm was found near the origin of a right intercostal artery immediately distal to the stenosis. $\overrightarrow{\vec{x}}$ The anomalies were less extensive than those in thefirst two patients, so that resection of the coarctation with the two aneurysms was not difficult. However, a graft had to be used to restore the continuity of the $\vec{C}$ aorta.

The post-operative course was uneventful, and $\mathrm{a}^{\circ}$ follow-up three years after operation revealed nothing abnormal. The blood pressure was $180 / 90 \mathrm{~mm}$. $\mathrm{Hg}$ in the arms and $160 / 100 \mathrm{~mm}$. $\mathrm{Hg}$ in the legs.

In these three patients, who did not develop $\overrightarrow{0}$ symptoms of coarctation until later in life, an? aneurysm developed which gravely increased the operative risk. In two patients this complication was partly responsible for the fatal issue. As has been pointed out, it is not only the prognosis of the untreated patients but also the risk and the results of surgical intervention that are importan

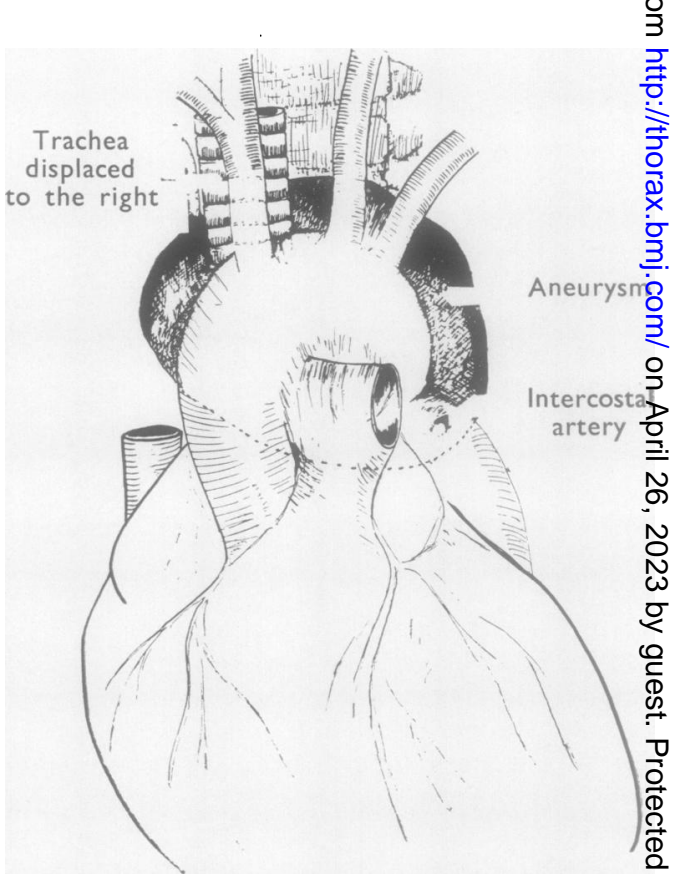

FIG. 2.-Large aneurysm arising from the first right intercostal artero beyond the stenosis. The trachea shows antero-lateral displace ment and flattening. 


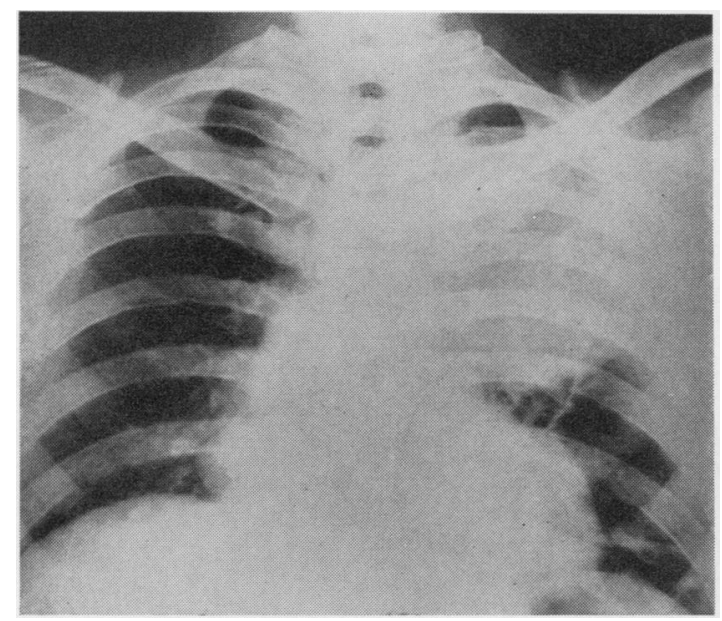

Fig. 3.-Large tumour at the level of the coarctation of the aorta caused by a pulsating ansurysm with a diameter of about $10 \mathrm{~cm}$.

in determining surgical indications in the treatment of coarctation of the aorta. To study the latter aspects, follow-up studies were made on our patients who had coarctation of the aorta and were over 35 when submitted to operation. Of the 386 patients submitted to resection since 1948, there were 32 ( 22 men and 10 women) of this age group. The oldest patient was 52. Only in one case was it necessary to restore the continuity of the aorta with a graft after resection of the stenosis. In all other cases an end-to-end anastomosis was performed.

\section{Mortality}

Two of the 32 patients were lost as a result of the operation.* One patient (aged 52) was the first case described above. The second patient was a man aged 35, who submitted to an operation in 1952 , after suffering for two years from palpitations, precordial pain, and dyspnoea of effort as much as from attacks of syncope. The brachial blood pressure was $155 / 120 \mathrm{~mm}$. $\mathrm{Hg}$. The femoral artery was not palpable.

At operation a stenosis was found in the aortic arch, between the left carotid and the left subclavian artery. Because of the position of the coarctation, the marked dilatation of the aorta past the stenosis, and the erroneous incision, it was only with difficulty that the stenosis could be resected and the continuity of the arch restored by an end-to-end anastomosis. The patient's general condition was initially satisfactory, but on the fifteenth post-operative day he suddenly developed violent pain in the left side and died shortly afterwards. Post-mortem examination revealed a large haematoma in the mediastinum; it had been caused by a perforated aneurysm at the side of the vascular suture.

*The patient aged 27, described on page 170 , has not been included in our statistics because he was under 35 years of age.

TABLE I

\begin{tabular}{|c|c|c|c|c|c|c|c|c|c|c|}
\hline \multirow{2}{*}{$\begin{array}{l}\text { Patient } \\
\text { No. }\end{array}$} & \multirow{2}{*}{$\begin{array}{l}\text { Age } \\
\text { (Yr.) }\end{array}$} & \multicolumn{2}{|c|}{$\begin{array}{l}\text { Blood Pressure } \\
\text { before Operation }\end{array}$} & \multicolumn{2}{|c|}{$\begin{array}{l}\text { Blood Pressure } \\
\text { after Operation }\end{array}$} & \multicolumn{2}{|c|}{$\begin{array}{l}\text { Rising Time External } \\
\text { Femoral Curve (sec.) }\end{array}$} & \multirow{2}{*}{\multicolumn{3}{|c|}{ Remarks }} \\
\hline & & Arm & Leg & Arm & Leg & $\begin{array}{c}\text { Before } \\
\text { Operation }\end{array}$ & $\begin{array}{c}\text { After } \\
\text { Operation }\end{array}$ & & & \\
\hline $\begin{array}{l}1 \\
2 \\
3 \\
4 \\
5 \\
6 \\
7 \\
8 \\
9 \\
10 \\
11 \\
12 \\
13 \\
14 \\
15 \\
16 \\
17 \\
18 \\
19 \\
20 \\
21 \\
22 \\
23 \\
24 \\
25 \\
26 \\
27 \\
28 \\
29 \\
30\end{array}$ & $\begin{array}{l}38 \\
46 \\
40 \\
36 \\
35 \\
39 \\
35 \\
37 \\
42 \\
35 \\
37 \\
46 \\
36 \\
36 \\
39 \\
43 \\
36 \\
44 \\
46 \\
36 \\
46 \\
41 \\
39 \\
38 \\
49 \\
42 \\
40 \\
41 \\
39 \\
35\end{array}$ & $\begin{array}{l}250 / 110 \\
200 / 95 \\
200 / 105 \\
220 / 110 \\
180 / 100 \\
200 / 90 \\
160 / 95 \\
220 / 105 \\
215 / 95 \\
250 / 105 \\
210 / 110 \\
240 / 100 \\
120 / 100 \\
170 / 90 \\
170 / 95 \\
250 / 120 \\
160 / 90 \\
140 / 105 \\
170 / 120 \\
125 / 100 \\
210 / 110 \\
150 / 90 \\
180 / 100 \\
180 / 80 \\
180 / 105 \\
170 / 110 \\
150 / 90 \\
180 / 105 \\
210 / 95 \\
160 / 100\end{array}$ & $\begin{array}{c}150: 110 \\
12590 \\
11090 \\
130 / 110 \\
130- \\
150 / 95 \\
130 / 90 \\
120 / 90 \\
10070 \\
120 / 90 \\
105 / 95 \\
8 \overline{80} 40 \\
150- \\
\overline{110} 85 \\
130- \\
150130 \\
10090 \\
11090 \\
120100 \\
130 \times 105 \\
11095 \\
11090\end{array}$ & $\begin{array}{l}165 / 90 \\
140 / 70 \\
14585 \\
150 / 90 \\
120 ' 65 \\
145 / 90 \\
135 / 90 \\
145 / 80 \\
180 / 90 \\
170 / 90 \\
160 / 90 \\
130 / 80 \\
120 / 95 \\
120 / 70 \\
120 / 80 \\
165 / 85 \\
130 / 75 \\
110 / 85 \\
130 / 80 \\
110,80 \\
130 / 85 \\
105 / 70 \\
160 / 80 \\
150,60 \\
130 / 100 \\
130 / 80 \\
120,60 \\
120 / 80 \\
160 / 95 \\
125 / 95\end{array}$ & $\begin{array}{l}180 / 110 \\
150 / 80 \\
155 / 95 \\
160 / 95 \\
135 / 90 \\
150 / 100 \\
150 / 95 \\
150 / 110 \\
160 / 100 \\
220 / 100 \\
180 / 100 \\
130 / 95 \\
130 / 95 \\
150 / 90 \\
140 / 110 \\
170 / 100 \\
155 / 110 \\
120 / 80 \\
150 / 100 \\
140 / 80 \\
160 / 90 \\
165 / 100 \\
180 / 120 \\
160 / 110 \\
160 / 100 \\
130 / 100 \\
140 / 90 \\
160 / 100 \\
170 / 100 \\
145 / 90\end{array}$ & 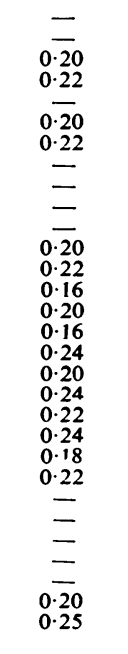 & $\begin{array}{l}0 \cdot 14 \\
0 \cdot 14 \\
0 \cdot 14 \\
0 \cdot 12 \\
0 \cdot 14 \\
0 \cdot 12 \\
0 \cdot 14 \\
\overline{0} \\
0 \cdot 20 \\
0 \cdot 14 \\
-\overline{0} \\
0 \cdot 14 \\
0 \cdot 20 \\
0 \cdot 12 \\
0 \cdot 14 \\
0 \cdot 12 \\
0 \cdot 14 \\
0 \cdot 20 \\
0 \cdot 18 \\
0 \cdot 14 \\
0 \cdot 12 \\
0 \cdot 14 \\
0 \cdot 12 \\
- \\
- \\
- \\
\overline{-} \\
0 \cdot 11 \\
0 \cdot 12\end{array}$ & , & $\ddot{\ddot{\prime}}$ & ", \\
\hline
\end{tabular}




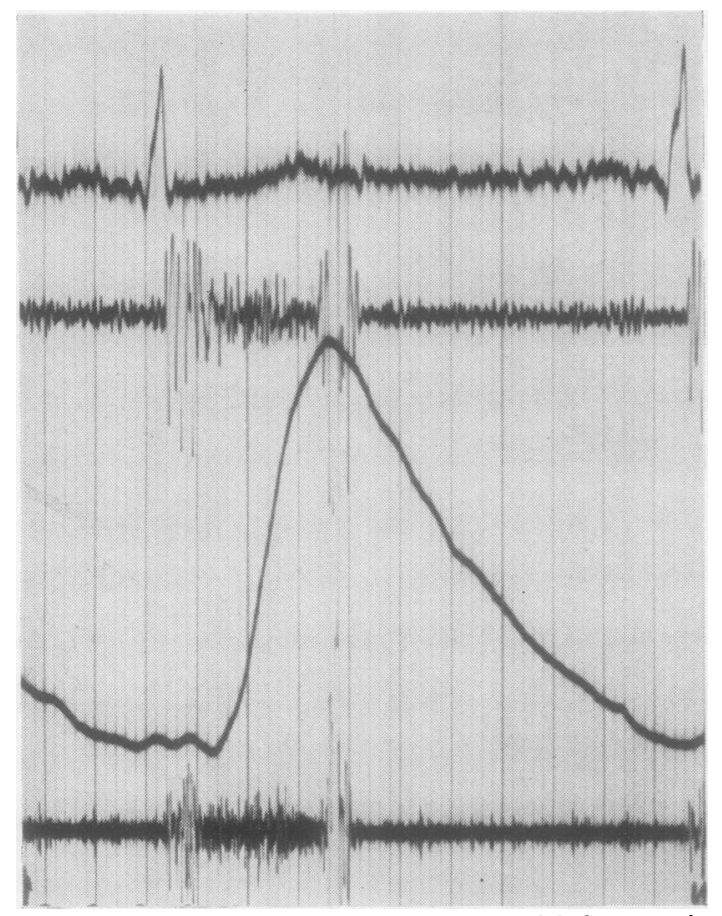

FIg. 4.-External femoral curve of patient No. 23 before resection of the coarctation. Rising time $0.22 \mathrm{sec}$.

\section{RESUlts OF THE OPERATION}

The 30 patients who survived the operation include 24 who were followed up for more than a year. Follow-up in the remaining six cases covered a period of six to 12 months.

In discussing the results of surgical treatment of coarctation of the aorta it should be borne in mind that the operation has a threefold purpose, viz., (1) resection of the stenosis, resulting in improvement of the circulation in the organs distal to the stenosis (kidneys, spinal cord, lower extremities) ; (2) diminution of the systolic blood pressure ; and (3) diminution of the diastolic blood pressure.

Resection of THE Stenosis.-Causes of death in untreated coarctation are rupture of an aneurysm of an intercostal artery ; sepsis, resulting from aortitis ; rupture of the aorta ; decompensation of the heart ; and rupture of an aneurysm of one of the arteries at the cerebral base. Resection of the stenosis prevents the occurrence of aneurysms in the aorta as a result of jet-lesion and the occurrence of aneurysms in the intercostal arteries. Moreover, the risk of an aortitis is reduced by resecting the stenosis.

To establish whether there was still stenosis of the aorta after the operation, the blood pressure was determined in the arms and in the legs at follow-up examination. In 23 cases the external femoral curve was recorded in addition. The results of this investigation are presented in Table I. In all cases the systolic pressure in the legs was found to exceed the pre-operative value. In all cases except one, moreover, it was found to be higher than, or equal to, the systolic pressure in the arms. In the one patient in whom the systolic pressure in the legs was lower than that in the arms, the continuity of the aorta had been restored with the aid of a graft. The external femoral curve also failed to show improvement in this patient. In 19 of the 23 patients in whom the femoral curve had been recorded, the rising time of the curve proved to have fallen to normal values (shorter than $0.15 \mathrm{sec}$.) (Figs. 4 and 5). Three of the four patients with an excessively long rising time of the femoral curve had in addition an aortic stenosis, which impeded interpretation of the curve.

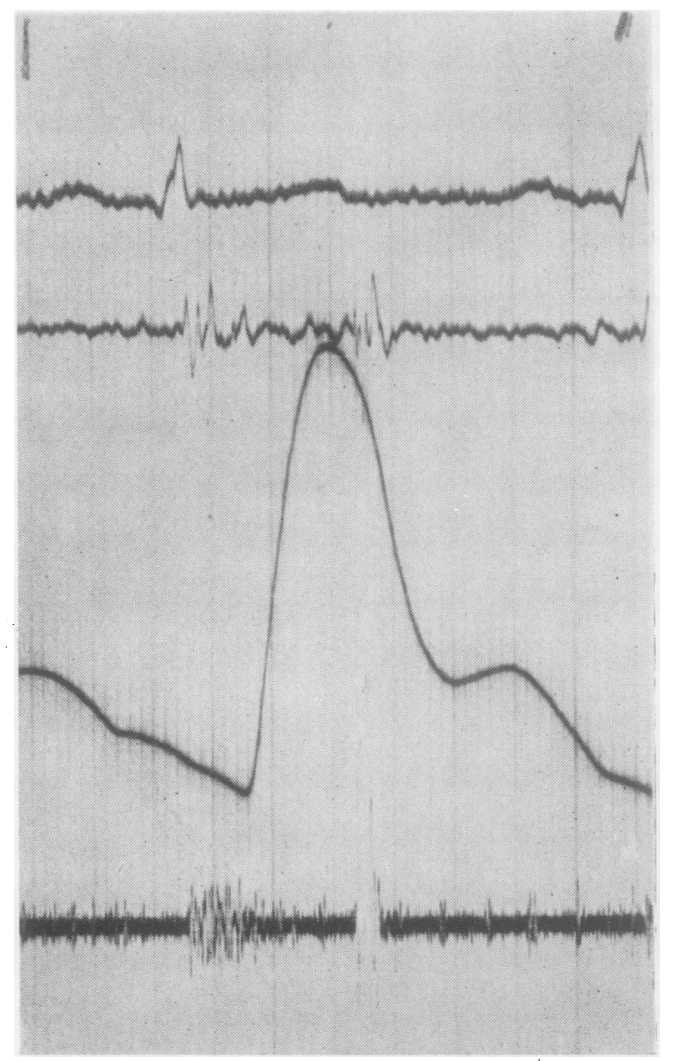

FIG. 5.-External femoral curve of patient No. 23 after the operation Rising time $0.12 \mathrm{sec}$. 
Diminution of Systolic Blood Pressure.It can be reasonably assumed that the risk of subarachnoid haemorrhage resulting from rupture of an aneurysm of one of the arteries at the cerebral base (cause of death in $10 \%$ of the fatal cases of Reifenstein et al.) is reduced as the systolic blood pressure decreases. Investigations made by Taylor and Donald (1960) have shown, moreover, that the post-operative rise in systolic pressure upon effort is less marked than the pre-operative rise upon effort. The results of the investigation into the influence of the operation on systolic and diastolic blood pressure are presented in Table I and in Figs. 6, 7, and 8 . All patients showed a post-operative decrease in systolic pressure, and in 25 of the 30 cases this was $160 \mathrm{~mm}$. $\mathrm{Hg}$ or less.

Diminution of Diastolic Blood Pressure.Of 104 patients with untreated coarctation of the aorta, 18 died from cardiac decompensation (Reifenstein et al.). A high diastolic pressure implies a high average systolic pressure. A high average systolic pressure implies a strain on the left ventricle (Sarnoff, Braunwald, Welch, Stainsby, Case, and Macruz, 1959). Diminution of the diastolic blood pressure, therefore, can improve the prognosis. Presuming that subjects with a diastolic pressure of $100 \mathrm{~mm} . \mathbf{H g}$ or more are suffering from essential hypertension, we find that 19 of the 30 patients examined by us had essential hypertension before the operation. Follow-up examinations showed that the diastolic pressure had returned to normal values $(95 \mathrm{~mm}$. $\mathrm{Hg}$ or less) after the operation in 18 of the 19 cases. Only in one patient did some slight essential hypertension persist (diastolic blood pressure $100 \mathrm{~mm}$. $\mathrm{Hg}$ ).

In all cases the E.C.G. findings were the same as those obtained before the operation. In 19 there was pre-operative hypertrophy or straining of the left ventricle. In two cases, post-operative E.C.G. examination showed that this strain had slightly diminished.

\section{Summary AND Conclusions}

The view that the prognosis of coarctation of the aorta in older patients without symptoms is reasonably good (Newman, 1948 ; Bramwell, 1947) and that a vascular suture entails graver risks in patients older than 25 years (Gross, 1953) caused us to be conservative in determining surgical indications in such patients.

The case histories of three patients given surgical treatment after having developed symptoms of systolic pressure

in $\mathrm{mmHg}$

\section{- systolic pressure before operation}

$\nabla$ systolic pressure after operation

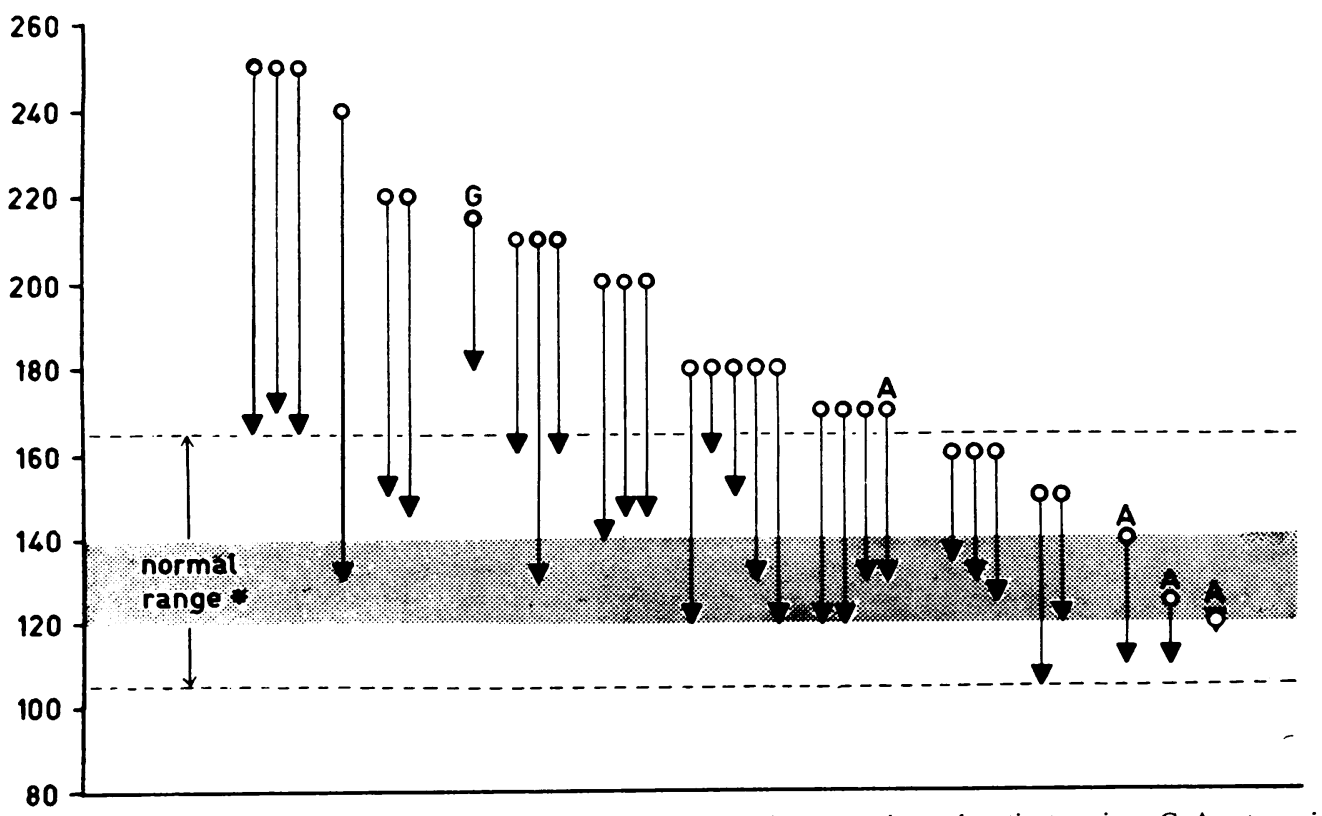

FIG. 6.-Systolic pressurefin the arm before and after operation. A, Patient with coarctation and aortic stenosis. G. Anastomosis with a graft. Normal range of systolic pressure after Hamilton. Pickering, Roberts, and Sowry (1954). 
diastolic pressure

- diastolic pressure before operation

in $\mathrm{mmHg}$

$\nabla$ - diastolic pressure after operation

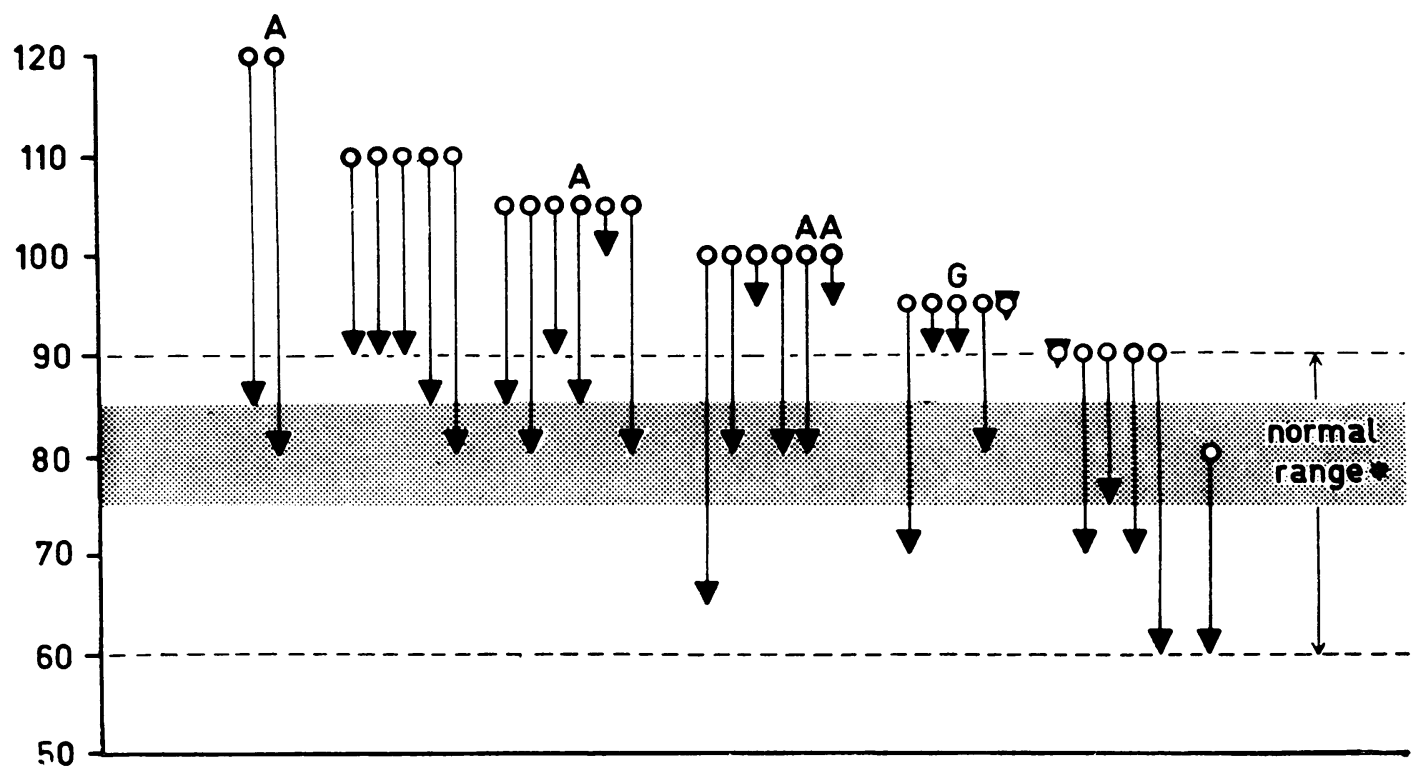

FIG. 7.-Diastolic pressure in the arm before and after operation. A, Patient with coarctation and aortic stenosis. G, Anastomosis with a graf Normal range of diastolic pressure after Hamilton et al. (1954).

systolic pressure

in $\mathrm{mmHg}$
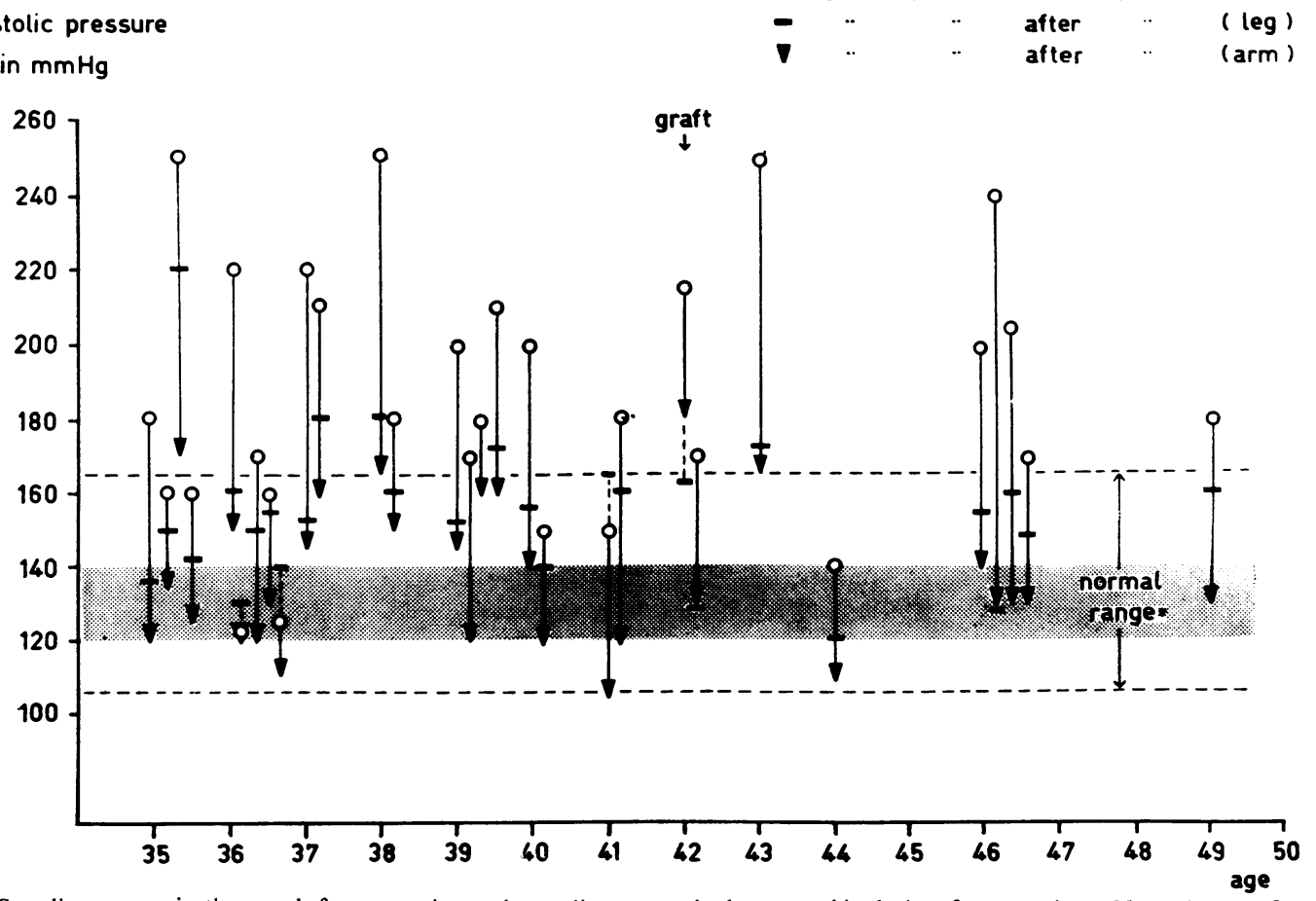

- systolic pressure before operation (arm)

(arm ) 
coarctation of the aorta at a more advanced age demonstrate that coarctation of the aorta can give rise to vitally dangerous complications in elderly patients.

Patients aged 35 and older (32 cases) were followed up. Two patients died as a result of the operation. The investigation showed: (1) The systolic pressure in the legs was found to be equal to or higher than that in the arms. (2) The systolic pressure in the arms had decreased in all patients. (3) In 18 of 19 patients with pre-operative diastolic hypertension, the pressure fell to below $100 \mathrm{~mm}$. $\mathrm{Hg}$ after the operation. (4) In 19 of 23 patients in whom the external femoral curve was recorded, the rising time of the curve proved to have decreased to within normal limits.

We believe that our findings warrant the following conclusions: There is certainly an indication for operation in patients more than 35 years old, even if the coarctation of the aorta has not yet given rise to symptoms. The surgical risk in these patients is acceptable. The results obtained justify the hope that the expectation of life will improve as a result of the operation.
Our thanks are due to Professor A. G. Brom for his interest in this paper and for his many helpful suggestions. We also express our gratitude to Dr. $\mathrm{H}$. Hartman and Dr. J. Krant, of the Department of Cardiology, for their help with the follow-up examinations.

\section{ADDENDUM}

After this paper had been written, another seven patients of more than 35 years of age underwent resection for coarctation without mortality.

\section{REFERENCES}

Bramwell, C. (1947). Brit. Heart J., 9, 100.

Crafoord, C., and Nylin, G. (1945). J. thorac. Surg., 14, 347.

Gross, R. E. (1953). Circulation, 7, 757.

and Hufnagel, C. A. (1945). New Engl. J. Med., 233, 287.

Groves, L. K., and Effler, D. B. (1960). J. thorac. Surg., 39, 60.

Hamilton, M., Pickering, G. W., Roberts, J. A. Fraser, and Sowry, G. S. C. (1954). Clin. Sci., 13, 11 .

Hamilton, W. F., and Abbott, M. E. (1928). Amer. Heart J., 3, 381

Newman, M. (1948). Brit. Heart J., 10, 150.

Reifenstein, G. H., Levine, S. A., and Gross, R. E. (1947). Amer. Heart J., 33, 146.

Sarnoff, S. J., Braunwald, E., Welch, G. H., Stainsby, W. N., Case, R. B., and Macruz, R. (1959). In Work and the Heart: Trans. First Wisconsin Conference on Work and the Heart, ed. F. F

Rosenbaum and E. L. Belknap, p. 18. Hoeber, New York.

Taylor, S. H., and Donald, K. W. (1960). Brit. Heart J., 22, 117. 